\title{
Hydrophilic perovskite microdisks with excellent stability and strong fluorescence for recyclable temperature sensing
}

\author{
Qing Luo, Hui Wang, Xiong Yin ${ }^{*}$ and Leyu Wang ${ }^{*}$
}

In recent years, metal halide perovskites have emerged as a promising new class of semiconductors for solar cells [1-3], light-emitting diodes (LED) [4-6], temperature sensors [7], lasers [8] and photodetectors [9], owing to their excellent optical and electronic properties [10,11], such as, long charge carrier diffusion length [12], high extinction coefficients and tunable band gaps [13]. However, the materials suffer from fast degradation due to their inherent instability [14-17], especially high sensitivity to oxygen [18], UV light [19,20], heat $[21,22]$, moisture $[23,24]$ and even some hydrophilic solvents such as alcohol, which significantly impedes their further applications [25,26]. Compared with organicinorganic hybrid perovskites [27], all-inorganic cesium lead halide perovskites $\mathrm{CsPbX}_{3}(\mathrm{X}=\mathrm{Cl}, \mathrm{Br}, \mathrm{I})$ are much stable [28-33], but the stability still needs substantial improvement to satisfy the needs of practical implications.

Up to now, the synthesis of perovskite materials is mainly based on the hot injection in hydrophobic solvents, such as oleylamine and toluene under inert atmospheres [34-37]. The mixture solvents usually could not be recycled and the as-obtained nanocrystals are highly sensitive to hydrophilic solvents such as ethanol and N,N-dimethylformamide (DMF) [34]. Therefore, the large-scale green production of these perovskite materials with excellent optical merits and good stability faces great challenges.

Herein, we report a solvothermal method for the largescale (1.5 g of product per $40 \mathrm{~mL}$ of solvents) synthesis of $\mathrm{Cs}_{4} \mathrm{PbBr}_{6} \mathrm{MDs}$ in DMF. Interestingly, the hydrophilic solvent DMF can be reutilized for tens of times and have no degradation on the products. The as-obtained $\mathrm{Cs}_{4} \mathrm{PbBr}_{6}$ MDs presented excellent fluorescence and outstanding stability. In addition, unlike the previously reported $\mathrm{CsPbX}_{3}(\mathrm{X}=\mathrm{Cl}, \mathrm{Br}, \mathrm{I})$ perovskites, the crystal structure of these $\mathrm{Cs}_{4} \mathrm{PbBr}_{6}$ MDs was well maintained under various temperatures. The temperature shows a great influence on the luminescent properties of luminescent materials. When the temperature increases, the non-radiation transition will be enhanced, resulting in the decrease of the intensity of the luminescence, which is known as thermal quenching [38,39]. The fluorescence of the $\mathrm{Cs}_{4} \mathrm{PbBr}_{6} \quad \mathrm{MDs}$ was quenched with the increased temperature. However, their fluorescence could be well recovered. In view of the excellent fluorescence and stability of $\mathrm{Cs}_{4} \mathrm{PbBr}_{6} \mathrm{MDs}$, a sensitive fluorescence sensor of temperature with good recyclability was developed, which was utilized for the temperature sensor in the range of $30-200^{\circ} \mathrm{C}$.

In the study, we developed a one-pot green wetchemistry strategy for large-scale synthesis of $\mathrm{Cs}_{4} \mathrm{PbBr}_{6}$ MDs. Briefly, the $\mathrm{CsBr}$ and $\mathrm{PbBr}_{2}$ were dissolved in $\mathrm{DMF}$ with polyvinylpyrrolidone (PVP) as the surfactant, and then the mixture was transferred into a Teflon-lined autoclave and treated at $150^{\circ} \mathrm{C}$ for $3 \mathrm{~h}$. Finally, the phasepure $\mathrm{Cs}_{4} \mathrm{PbBr}_{6} \mathrm{MDs}$ with strong green fluorescence and hydrophilic surface were obtained (Fig. 1a). The X-ray powder diffraction (XRD) measurement was carried out to determine the accurate phases of the as-obtained products. As shown in Fig. 1b, from MD-1 to MD-4, the molar ratio of $\mathrm{CsBr}$ to $\mathrm{PbBr}_{2}$ in the precursors for the synthesis of samples was 7, 6, 5 and 4, respectively. The peaks at $29.4^{\circ}, 42.1^{\circ}$ and $52.1^{\circ}$ can be indexed to $\mathrm{CsBr}$, which became weak by decreasing the molar ratio of CsBr-to- $\mathrm{PbBr}_{2}$. The diffraction peaks of the perovskites became sharper and much more intense from MD-1 to MD-4, suggesting the good crystallinity of as-prepared

State Key Laboratory of Chemical Resource Engineering, Innovation Centre for Soft Matter Science and Engineering, Beijing University of Chemical Technology, Beijing 100029, China

* Corresponding authors (emails: yinxiong@mail.buct.edu.cn (Yin X); lywang@mail.buct.edu.cn (Wang L)) 


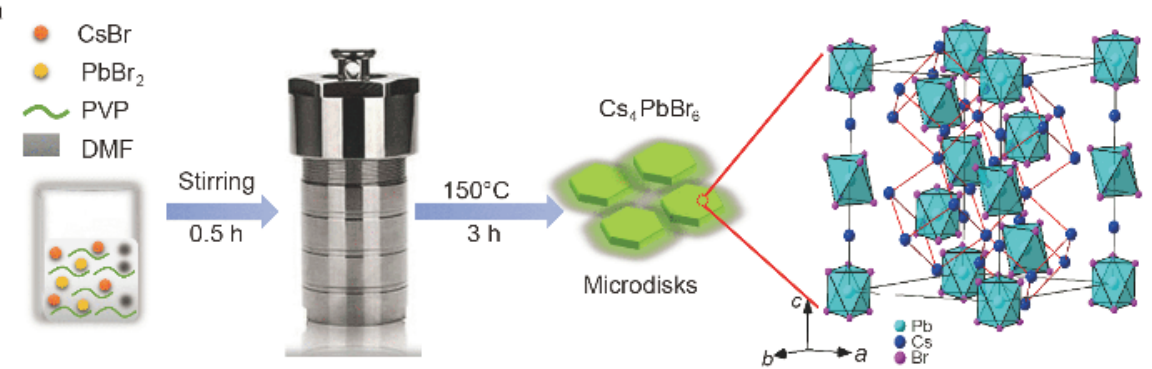

b

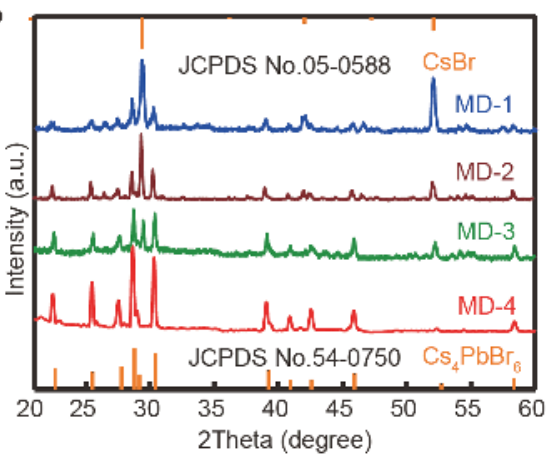

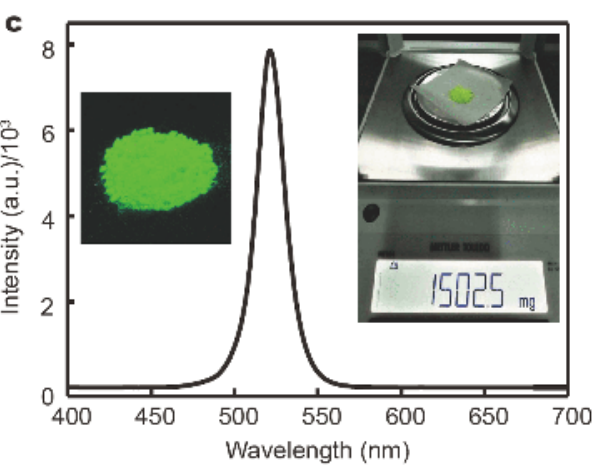

Figure 1 Scheme for the synthesis process (a), XRD patterns (b) and fluorescence spectrum and photograph (c) of $\mathrm{Cs}_{4} \mathrm{PbBr}_{6} \mathrm{MDs}_{\text {. }}(\mathrm{b})$ From $\mathrm{MD}-1$ to MD-4, the molar ratio of $\mathrm{CsBr}$-to- $\mathrm{PbBr}_{2}$ in the precursor was 7, 6, 5 and 4, respectively.

samples. All the diffraction peaks of the perovskites were well assigned to those of $\mathrm{Cs}_{4} \mathrm{PbBr}_{6}$ (JCPDS number: 540750). And no impurity peaks were observed in the XRD patterns of MD-4, which confirms the high purity of the products when the molar ratio of CsBr-to- $\mathrm{PbBr}_{2}$ was 4:1. The typical photoluminescence (PL) spectrum (Fig. 1c) and ultraviolet-visible (UV-vis) absorption spectrum (Fig. S1) were also obtained. A sharp and symmetric of PL spectrum located at $521.4 \mathrm{~nm}$ with a full width at half maximum (FWHM) of $20 \mathrm{~nm}$ was observed. The insets in Fig. 1c showed the photographs of $\mathrm{Cs}_{4} \mathrm{PbBr}_{6}$ powders under UV light (left, $\lambda_{\mathrm{ex}}=365 \mathrm{~nm}$ ) and the products prepared on a large scale (right, $1.5 \mathrm{~g}$ ) in one autoclave ( $40 \mathrm{~mL}$ of DMF). Obviously, the $\mathrm{Cs}_{4} \mathrm{PbBr}_{6}$ powders showed very bright green fluorescence, with a photoluminescence quantum yield (PLQY) of $42 \%$ (Fig. S2). It is noteworthy that the solvent (DMF) could be reutilized for tens of times. There is no difference on the shape and size of the as-obtained $\mathrm{Cs}_{4} \mathrm{PbBr}_{6}$ MDs (Fig. S3). Meanwhile, their fluorescence is also as strong as that of the $\mathrm{Cs}_{4} \mathrm{PbBr}_{6}$ MDs synthesized using fresh DMF, although the wavelength of fluorescence had a slight fluctuation $(526.8 \pm 1.6 \mathrm{~nm})$ (Figs S4-S6).

The typical transmission electron microscopy (TEM) and scanning electron microscopy (SEM) images of the as-synthesized $\mathrm{Cs}_{4} \mathrm{PbBr}_{6}$ were shown in Fig. 2. As presented in Fig. $2 \mathrm{a}$ and b, the $\mathrm{Cs}_{4} \mathrm{PbBr}_{6}$ MDs presented a disk shape with an average diameter of $\sim 1 \mu \mathrm{m}$ and thickness of $\sim 100 \mathrm{~nm}$. Moreover, the energy-dispersive $\mathrm{X}$-ray (EDX) elemental mapping of $\mathrm{Cs}, \mathrm{Pb}$ and $\mathrm{Br}$ (Fig. 2c-f) confirmed the existence and uniform distribution of the elements within the disk. Elemental ratio of $\mathrm{Cs}: \mathrm{Pb}: \mathrm{Br}$ in an individual disk as obtained from EDX spectroscopy (Fig. S7) is calculated to be 4.03:1:6.07, which is in good consistence with the $\mathrm{Cs}_{4} \mathrm{PbBr}_{6}$ composition observed from XRD. Consequently, the $\mathrm{Cs}_{4} \mathrm{PbBr}_{6} \mathrm{MDs}$ with uniform morphology and high phase purity were synthesized via this one-pot green strategy.

It is well known the long-term stability of perovskites is the key issue in perovskite-based devices, considering the intrinsic degradation under real working conditions, where the device is operated continuously with light and heat. Therefore, the thermal stability of these perovskite MDs was carefully investigated. As shown in Fig. 3a, the fluorescence of $\mathrm{Cs}_{4} \mathrm{PbBr}_{6}$ powders showed a negligible decrease after heating at $200^{\circ} \mathrm{C}$ for $2 \mathrm{~h}$ and then naturally cooling to room temperature $\left(30^{\circ} \mathrm{C}\right)$, which was further confirmed by the PL spectra with a PLQY of $38 \%$ (Fig. S8). Meanwhile, no obvious changes were observed in the color of the perovskite powder under natural light. On the contrary, the fluorescence of $\mathrm{CsPbBr}_{3}$ QDs, synthesized using hot injection in hydrophobic solvents, 


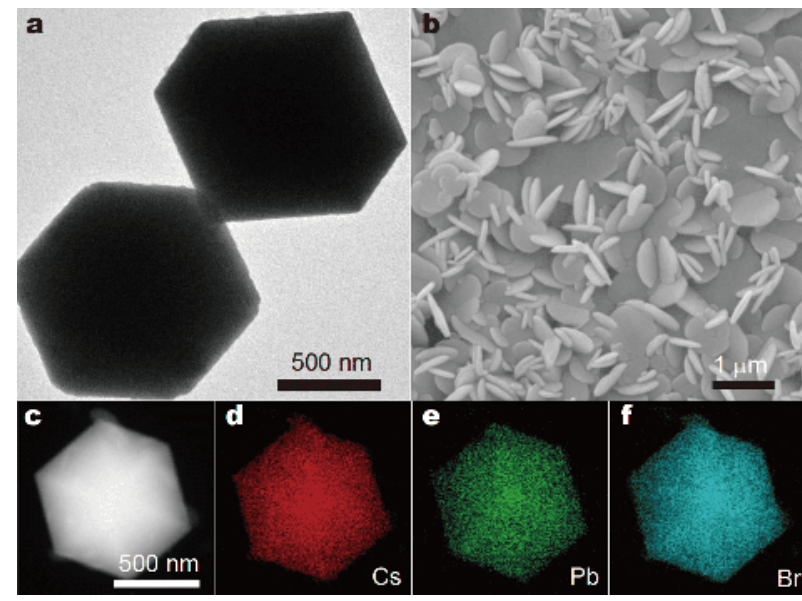

Figure 2 TEM (a) and SEM (b) images and elemental mapping images (c) of as-prepared $\mathrm{Cs}_{4} \mathrm{PbBr}_{6}$ MDs.

was completely quenched after heating treatment with the same process (Fig. 3a and Fig. S9), and their color was evolved into yellow under natural light. To reveal the reason that $\mathrm{Cs}_{4} \mathrm{PbBr}_{6}$ crystals remained the luminescence property after heating treatment, we investigated the crystal structure of $\mathrm{Cs}_{4} \mathrm{PbBr}_{6}$ powder by means of temperature-dependent XRD measurement. As shown in Fig. 3b, the XRD peaks matched well with the $\mathrm{Cs}_{4} \mathrm{PbBr}_{6}$ reflections at the temperatures ranging from 30 to $200^{\circ} \mathrm{C}$. A slight shift of peak could be attributed to the lattice expansion with temperature increment. However, the crystal structure of $\mathrm{CsPbBr}_{3}$ QDs was completely destroyed after the heating treatment (Fig. S10). Fig. 3c shows the temperature-dependent fluorescence spectra at room temperature and $200^{\circ} \mathrm{C}$. More importantly, the fluorescence intensity of $\mathrm{Cs}_{4} \mathrm{PbBr}_{6}$ sample was well maintained after 20 heating-cooling cycles (Fig. 3d), implying the excellent thermal stability of as-prepared $\mathrm{Cs}_{4} \mathrm{PbBr}_{6}$ MDs. The results demonstrate that the thermal responsive fluorescence performance of $\mathrm{Cs}_{4} \mathrm{PbBr}_{6}$ powder could be attributed to thermal quenching instead of the changes in structure at high temperature [38].

Encouraged by the above-mentioned results, $\mathrm{Cs}_{4} \mathrm{PbBr}_{6} /$ polydimethylsiloxane (PDMS) composites were further fabricated via thermal polymerization and then applied for temperature sensing. As shown in Fig. 4a, the composite disk showed uniform bright green luminescence with excellent recovery ability after heating-cooling cycle between 30 and $200^{\circ} \mathrm{C}$. To deeply investigate the feasibility of this luminescent disk for temperature sensing, the temperature-dependent PL was carefully checked. As depicted in Fig. 4b, no obvious red or blue shift was observed in the fluorescence spectra of the
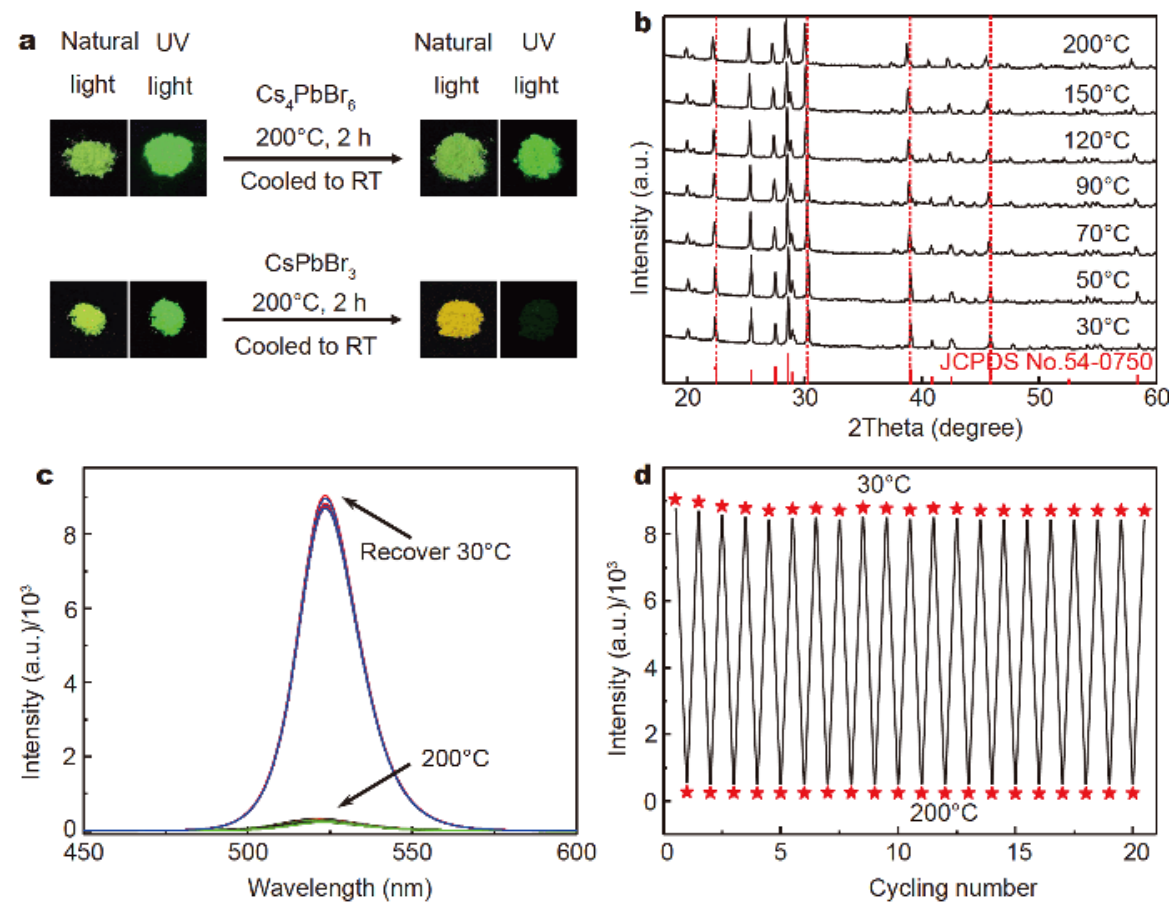

Figure 3 (a) Photographs of $\mathrm{Cs}_{4} \mathrm{PbBr}_{6} \mathrm{MDs}$ and $\mathrm{CsPbBr}_{3}$ nanocrystals under natural light and $\mathrm{UV}$ light before and after heating treatment at $200^{\circ} \mathrm{C}$ for $2 \mathrm{~h}$; (b) XRD patterns of the $\mathrm{Cs}_{4} \mathrm{PbBr}_{6} \mathrm{MDs}$ at various temperatures; (c) Fluorescence spectra and (d) fluorescence intensity evolution of the $\mathrm{Cs}_{4} \mathrm{PbBr}_{6} \mathrm{MDs}$ during tens of heating-cooling cycles between 30 and $200^{\circ} \mathrm{C}$. 
a
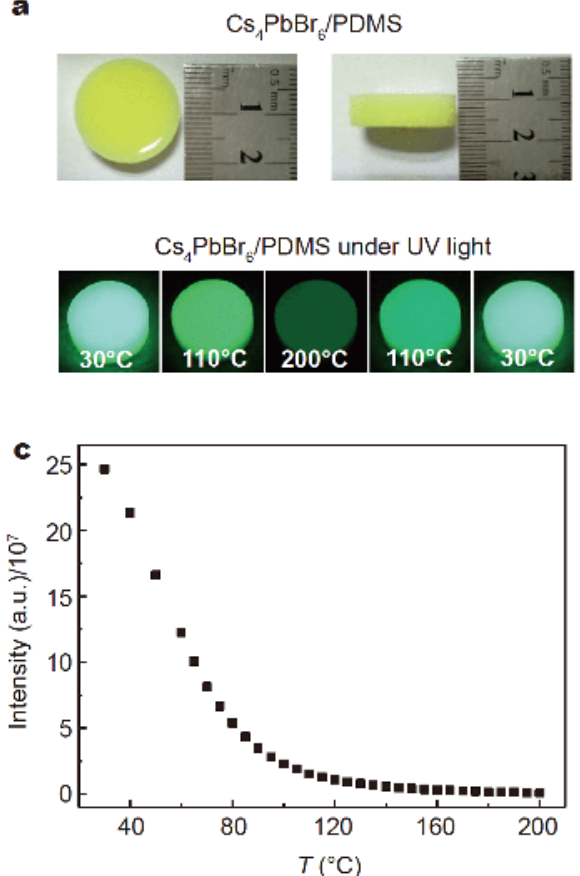
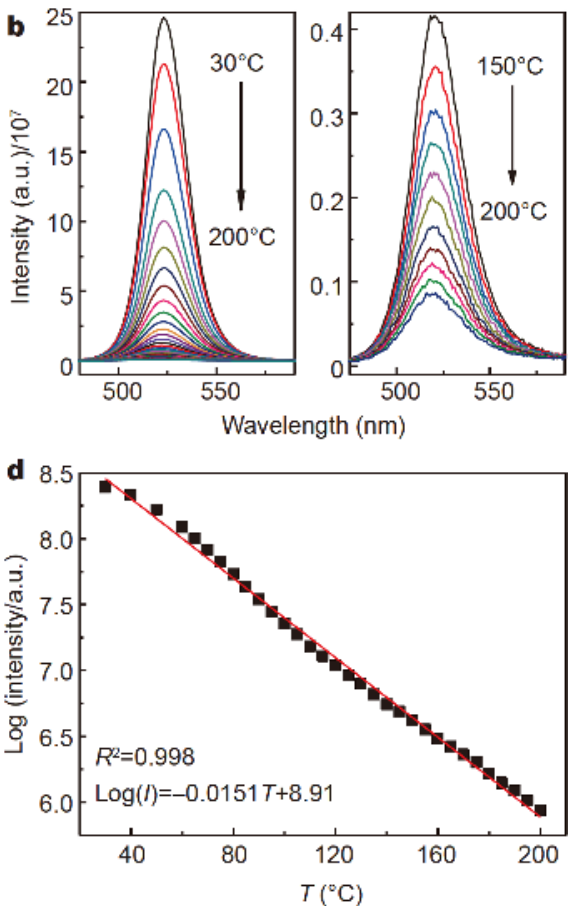

Figure 4 Photographs of $\mathrm{Cs}_{4} \mathrm{PbBr}_{6} / \mathrm{PDMS}$ composite under natural light and UV light (a); fluorescence spectra (b) and peak intensity (c) of $\mathrm{Cs}_{4} \mathrm{PbBr}_{6} /$ PDMS composite under different temperatures; (d) Linear relationship plot between natural logarithm of luminescence intensity and temperature.

$\mathrm{Cs}_{4} \mathrm{PbBr}_{6} / \mathrm{PDMS}$ composite at various temperatures. However, the fluorescence intensity (I) exponentially decreased with the temperature increment (Fig. 4c). Interestingly, the natural logarithm of luminescence intensity $(\log (I))$ and the temperature $(T)$ fell into the linear plot $\left(R^{2}=0.9980\right)$, as indicated in Fig. $4 \mathrm{~d}$, demonstrating that the luminescent $\mathrm{Cs}_{4} \mathrm{PbBr}_{6} / \mathrm{PDMS}$ composite can be utilized for temperature sensing [39].

In summary, we developed a one-step green strategy for the large-scale production of pure phase $\mathrm{Cs}_{4} \mathrm{PbBr}_{6}$ MDs in hydrophilic solvent (DMF) with excellent fluorescent merits and thermal stability. The solvent can be reutilized for tens of times without degrading the final perovskite products. These $\mathrm{Cs}_{4} \mathrm{PbBr}_{6} \mathrm{MDs}$ demonstrated an outstanding thermal stability, which is in favour of the heat processing of the perovskite-based devices. Meanwhile, the samples showed excellent fluorescence recovery after cooling to room temperature from $200^{\circ} \mathrm{C}$. Owing to these merits, a luminescent sensor using $\mathrm{Cs}_{4} \mathrm{PbBr}_{6} / \mathrm{PDMS}$ composite was fabricated for the fluorescence sensing of temperature. Furthermore, the temperature-dependent $\mathrm{XRD}$ results confirmed that the thermal responsive fluorescence of $\mathrm{Cs}_{4} \mathrm{PbBr}_{6} \mathrm{MDs}$ stemmed from thermal quenching instead of structure change at high temperature. We believe this work will promote tremendous advances for further developing the large-scale green synthesis of perovskites and push all-inorganic halide perovskites to a new stage as a research paradigm in the field of optoelectronic devices, especially in perovskitebased temperature sensing, healthy lighting and widecolour-gamut displays.

Received 12 November 2018; accepted 14 January 2019; published online 29 January 2019

1 Hou Y, Du X, Scheiner S, et al. A generic interface to reduce the efficiency-stability-cost gap of perovskite solar cells. Science, 2017, 358: $1192-1197$

2 Chen $\mathrm{H}$, Ye F, Tang W, et al. A solvent- and vacuum-free route to large-area perovskite films for efficient solar modules. Nature, 2017, 131: 92-95

$3 \mathrm{Xu} \mathrm{Z}$, Yin X, Guo Y, et al. Ru-Doping in $\mathrm{TiO}_{2}$ electron transport layers of planar heterojunction perovskite solar cells for enhanced performance. J Mater Chem C, 2018, 6: 4746-4752

4 Abdi-Jalebi M, Andaji-Garmaroudi Z, Cacovich S, et al. Maximizing and stabilizing luminescence from halide perovskites with potassium passivation. Nature, 2018, 555: 497-501

5 Chin XY, Perumal A, Bruno A, et al. Self-assembled hierarchical nanostructured perovskites enable highly efficient LEDs via an energy cascade. Energy Environ Sci, 2018, 11: 1770-1778

6 Ng YF, Kulkarni SA, Parida S, et al. Highly efficient Cs-based perovskite light-emitting diodes enabled by energy funnelling. Chem Commun, 2017, 53: 12004-12007

7 Saidaminov MI, Almutlaq J, Sarmah S, et al. Pure $\mathrm{Cs}_{4} \mathrm{PbBr}_{6}$ : highly 
luminescent zero-dimensional perovskite solids. ACS Energy Lett, 2016, 1: 840-845

8 Karl M, Glackin JME, Schubert M, et al. Flexible and ultra-lightweight polymer membrane lasers. Nat Commun, 2018, 9: 1525

9 Chen Q, Wu J, Ou X, et al. All-inorganic perovskite nanocrystal scintillators. Nature, 2018, 561: 88-93

10 Zhao Y, Zhu K. Organic-inorganic hybrid lead halide perovskites for optoelectronic and electronic applications. Chem Soc Rev, 2016, 45: 655-689

11 Su X, Ma H, Wang H, et al. Surface-enhanced Raman scattering on organic-inorganic hybrid perovskites. Chem Commun, 2018, 54: 2134-2137

12 Chen Y, Yi HT, Wu X, et al. Extended carrier lifetimes and diffusion in hybrid perovskites revealed by hall effect and photoconductivity measurements. Nat Commun, 2016, 7: 12253

13 Lou Y, Fang M, Chen J, et al. Formation of highly luminescent cesium bismuth halide perovskite quantum dots tuned by anion exchange. Chem Commun, 2018, 54: 3779-3782

14 Cho H, Kim YH, Wolf C, et al. Improving the stability of metal halide perovskite materials and light-emitting diodes. Adv Mater, 2018, 30: 1704587

$15 \mathrm{Wu} \mathrm{Y}$, Wei $\mathrm{Y}$, Huang $\mathrm{Y}$, et al. Capping $\mathrm{CsPbBr}_{3}$ with $\mathrm{ZnO}$ to improve performance and stability of perovskite memristors. Nano Res, 2016, 10: 1584-1594

16 Xue M, Zhou H, Xu Y, et al. High-performance ultraviolet-visible tunable perovskite photodetector based on solar cell structure. Sci China Mater, 2017, 60: 407-414

17 Li X, Xue Z, Luo D, et al. A stable lead halide perovskite nanocrystals protected by PMMA. Sci China Mater, 2018, 61: 363-370

18 Stoeckel MA, Gobbi M, Bonacchi S, et al. Reversible, fast, and wide-range oxygen sensor based on nanostructured organometal halide perovskite. Adv Mater, 2017, 29: 1702469

19 Ummadisingu A, Steier L, Seo JY, et al. The effect of illumination on the formation of metal halide perovskite films. Nature, 2017, 545: 208-212

20 Wang $\mathrm{B}$, Zhang $\mathrm{C}$, Huang $\mathrm{S}$, et al. Postsynthesis phase transformation for $\mathrm{CsPbBr} 3 / \mathrm{Rb}_{4} \mathrm{PbBr}_{6}$ core/shell nanocrystals with exceptional photostability. ACS Appl Mater Interfaces, 2018, 10: 2330323310

21 Tan W, Bowring AR, Meng AC, et al. Thermal stability of mixed cation metal halide perovskites in air. ACS Appl Mater Interfaces, 2018, 10: 5485-5491

22 Li X, Wang Y, Sun H, et al. Amino-mediated anchoring perovskite quantum dots for stable and low-threshold random lasing. Adv Mater, 2017, 29: 1701185

23 Wang H, Yin X, Wang L. Highly stable perovskite nanogels as inks for multicolor luminescent authentication applications. J Mater Chem C, 2018, 6: 11569-11574

24 Li Y, Wang Y, Zhang T, et al. Li dopant induces moisture sensitive phase degradation of an all-inorganic $\mathrm{CsPbI}_{2} \mathrm{Br}$ perovskite. Chem Commun, 2018, 54: 9809-9812

25 Correa-Baena JP, Saliba M, Buonassisi T, et al. Promises and challenges of perovskite solar cells. Science, 2017, 358: 739-744

26 Rong Y, Hu Y, Mei A, et al. Challenges for commercializing perovskite solar cells. Science, 2018, 361: eaat8235

27 Nishikubo R, Tohnai N, Hisaki I, et al. Thermoresponsive emission switching via lower critical solution temperature behavior of or- ganic-inorganic perovskite nanoparticles. Adv Mater, 2017, 29: 1700047

28 Smock SR, Williams TJ, Brutchey RL. Quantifying the thermodynamics of ligand binding to $\mathrm{CsPBBr}_{3}$ quantum dots. Angew Chem Int Ed, 2018, 57: 11711-11715

29 Song J, Li J, Li X, et al. Quantum dot light-emitting diodes based on inorganic perovskite cesium lead halides $\left(\mathrm{CsPbX}_{3}\right)$. Adv Mater, 2016, 27: 7162-7167

30 Chen X, Peng L, Huang $\mathrm{K}$, et al. Non-injection gram-scale synthesis of cesium lead halide perovskite quantum dots with controllable size and composition. Nano Res, 2016, 9: 1994-2006

31 Yang $\mathrm{P}$, Liu G, Liu B, et al. All-inorganic $\mathrm{Cs}_{2} \mathrm{CuX}_{4}(\mathrm{X}=\mathrm{Cl}, \mathrm{Br}$, and $\mathrm{Br} / \mathrm{I})$ perovskite quantum dots with blue-green luminescence. Chem Commun, 2018, 54: 11638-11641

32 Zhou L, Liao JF, Huang ZG, et al. All-inorganic lead-free $\mathrm{Cs}_{2} \mathrm{PdX}_{6}$ $(\mathrm{X}=\mathrm{Br}, \mathrm{I})$ perovskite nanocrystals with single unit cell thickness and high stability. ACS Energy Lett, 2018, 3: 2613-2619

33 Zhou L, Xu YF, Chen BX, et al. Synthesis and photocatalytic application of stable lead-free $\mathrm{Cs}_{2} \mathrm{AgBiBr}_{6}$ perovskite nanocrystals. Small, 2018, 14: 1703762

34 Protesescu L, Yakunin S, Bodnarchuk MI, et al. Nanocrystals of cesium lead halide perovskites $\left(\mathrm{CsPb}_{3}, \mathrm{X}=\mathrm{Cl}, \mathrm{Br}\right.$, and $\left.\mathrm{I}\right)$ : novel optoelectronic materials showing bright emission with wide color gamut. Nano Lett, 2016, 15: 3692-3696

35 Zhang D, Eaton SW, Yu Y, et al. Solution-phase synthesis of cesium lead halide perovskite nanowires. J Am Chem Soc, 2015, 137: 9230-9233

36 Nedelcu G, Protesescu L, Yakunin S, et al. Fast anion-exchange in highly luminescent nanocrystals of cesium lead halide perovskites $(\mathrm{CsPbX}, \mathrm{X}=\mathrm{Cl}, \mathrm{Br}, \mathrm{I})$. Nano Lett, 2015, 15: 5635-5640

$37 \mathrm{Xu} \mathrm{W}$, Cai Z, Li F, et al. Embedding lead halide perovskite quantum dots in carboxybenzene microcrystals improves stability. Nano Res, 2017, 10: 2692-2698

38 McLaurin EJ, Bradshaw LR, Gamelin DR. Dual-emitting nanoscale temperature sensors. Chem Mater, 2013, 25: 1283-1292

39 Wang X, Wolfbeis OS, Meier RJ. Luminescent probes and sensors for temperature. Chem Soc Rev, 2013, 42: 7834-7869

Acknowledgements This research was supported by the National Natural Science Foundation of China (21725501, 21675009, 21771019 and 21521005) and the Fundamental Research Funds for the Central Universities (buctrc201706, buctrc201812 and buctrc201815). We also thank the support from the Public Hatching Platform for Recruited Talents of Beijing University of Chemical Technology.

Author contributions Luo Q and Wang $\mathrm{H}$ performed the main experiments; Wang $\mathrm{L}$ and Yin $\mathrm{X}$ conceived and supervised the project; Luo $\mathrm{Q}$ and Wang $\mathrm{H}$ wrote the manuscript with support from Yin $\mathrm{X}$ and Wang L. All authors contributed to the general discussion.

Conflict of interest The authors declare no conflict of interest.

Supplementary information Supporting data are available in the online version of the paper. Experimental section; UV-vis absorption spectra, PLQY, TEM images, photographs, fluorescence spectra, fluorescence peak wavelength and EDX spectroscopy of $\mathrm{Cs}_{4} \mathrm{PbBr}_{6}$ sample; fluorescence spectra and XRD patterns of $\mathrm{CsPBBr}_{3}$ nanocrystals. 

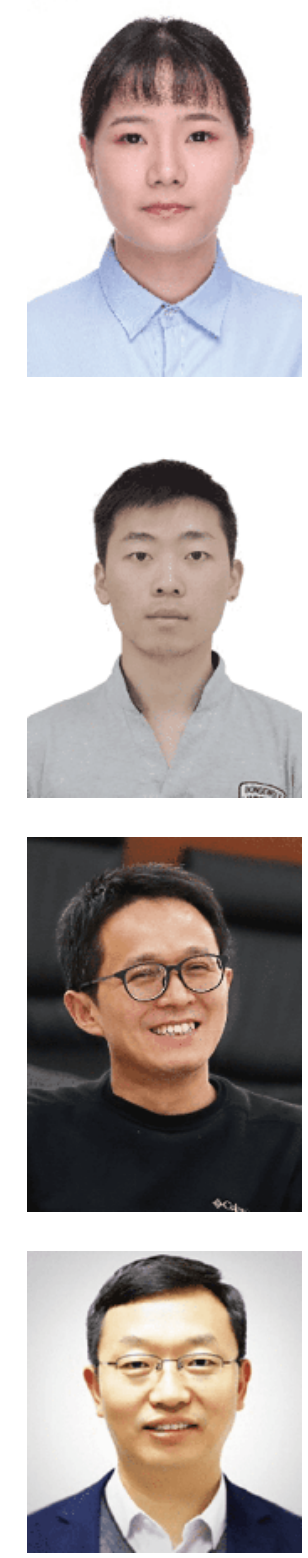

Qing Luo is currently a master candidate in chemistry at Beijing University of Chemical Technology (BUCT). She received her BSc from the BUCT in 2017. Her research interest focuses on exploring nanomaterials for energy conversion and catalysis applications.
Hui Wang currently is a PhD candidate in chemistry under the supervision of Prof. Leyu Wang at BUCT. His research projects focus on the design and fabrication of nanostructures for photoelctrical catalysis, sensing and bio-imaging.

Xiong Yin is an associate professor of chemistry at BUCT. He received his PhD in physical chemistry (2008) from the Institute of Chemistry, Chinese Academy of Sciences. In 2009, he became a postdoctoral researcher at the National University of Singapore, and then a staff scientist at the National Center for Nanoscience and Technology (NCNST), China, in 2010. He joined the faculty at the School of Science, BUCT in 2016. He was also a visiting scholar at the Yamagata University in 2012, the University of California, Los Angeles in 2013 and the University of California, Riverside from 2015 to 2016. His research interest includes perovskite-based solar cells, biochemical sensing and synthesis of lowcost catalysts for energy conversion application.

Leyu Wang is a professor of chemistry at BUCT. He has been supported by "the National Natural Science Foundation of China for Distinguished Young Scholar". He received his PhD in chemistry from Tsinghua University in 2007. Then he joined University of California at Los Angeles (UCLA) as a postdoctoral researcher from 2007 to 2009. He moved to BUCT's Department of Chemistry in October, 2009. His research interests span from the controlled synthesis of luminescent nanoparticles, LSPR semiconductor nanomaterials, magnetic nanomaterials, metal-semiconductor heteronanostructures, and multifunctional nanoprobes to the applications including electrocatalysis, artificial photosynthesis, biochemical sensing, multimodal imaging, drug/gene delivery and photothermo/chemo therapy. Prof. Wang has published over 130 research papers in journals and also held over 27 patents.

\title{
超稳定强苂光亲水钙钓矿薄片的制备及热传感性能研究
}

\author{
罗清, 王辉, 殷雄", 汪乐余"
}

摘要 铯铅卤化物钻针矿材料因具有优异的光学特性, 近年来受到广泛关注, 但其固有的不稳定性及现有的制备技术阻碍了它们的实际 应用. 本文报道了一种大规模绿色合成亲水钙铁矿 $\mathrm{Cs}_{4} \mathrm{PbBr}_{6}$ 薄片的方法. 本方法用 $N, N-$ 二甲基甲酰胺作为可循环使用的溶剂, 所得到的铯

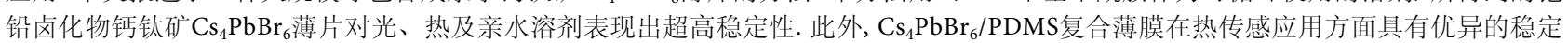
性和再现性. 本研究为制备高稳定性钻钛矿材料提供了有效的参考途径. 